\title{
Performance and Efficiency Evaluations of International Hotels in Taipei
}

\author{
Lung-Tan $\mathrm{Lu}^{1}$ \\ ${ }^{1}$ Department of Management, Fo Guang University, Taiwan \\ Correspondence: Lung-Tan Lu, Department of Management, Fo Guang University, Taiwan. Tel: 886-3-987-1000. \\ E-mail: 1tlu@mail.fgu.edu.tw
}

\author{
Received: May 16, 2015 \\ doi:10.5539/ijef.v7n7p64
}

Accepted: June 18, 2015

Online Published: June 25, 2015

URL: http://dx.doi.org/10.5539/ijef.v7n7p64

\begin{abstract}
The aim of this paper is to examine the performance and efficiency changes of international hotels in Taipei. Data Envelopment Analysis (DEA) is applied to a sample of international hotels in Taipei between 2000 and 2015. Malmquist Index is used to evaluate the relative importance of productivity changes. Five input variables (i.e. numbers of rooms, number of employee at administration department, number of employee at $\mathrm{F} \& \mathrm{~B}$ department, number of employee at room department, number of employee at other departments,) and one output variable: total revenues are used in this model. The results showed that 2008 financial crisis did strongly impact performance for international hotels in Taipei in terms of TEC, SEC and TFPC, but did not seem to have great impact on the Technical efficiency change (TEC), Technical change (TC), Pure technical change (PTC), Scale efficiency change (SEC) and Total factor productivity change (TFPC) for the international hotels in Taipei. It is found that the international hotel with highest total factor productivity change (TFPC) intensification is Imperial Hotel Taipei over the period of 2000-2015. On the contrary, First Hotel had the lowest total factor productivity change (TFPC). Managerial implications and suggestion are discussed in the final section.
\end{abstract}

Keywords: hotel, operational performance, data envelopment analysis, malmquist productivity index

\section{Introduction}

In accordance with the UNWTO Annual Report, tourism has become a one of major sources of foreign exchange earnings for many countries around the world (World Tourism Organization, 2010). According to the Global Destination Cities Index by MasterCard Company in a ranking of the 132 most visited cities around the world, London has maintained its position as the top-ranked international travel destination in 2015 and Taipei was ranked as 16th. However, if we observe Fastest Growing Destination Cities between 2009 and 2015, Four out of five cities are in Asia led by Taipei, which are still growing at double digits. And for the four Asian cities, their strong growth in international visitors has come typically from the huge increase in outbound travelers from China.

In 1956, Taiwanese Government formally instigated the tourism sector. By the joint endeavors of the government and the service sector, the tourism industry has scored a considerable expansion in the end of 20th century. However, the most essential component of the tourism industry, was the hotel business (Chang \& Lu, 2006; Giannotti et al., 2010). Based on the results of the foreign visitors' survey in Taiwan between 2000 and 2013 , each passenger daily spent US\$ 224.07 and stays 6.86 nights in 2013 (Tourism Bureau, the Ministry of Transportation, 2014). Thus, it can be seen that the business of tourism hotels played an important role tourism industry in Taiwan.

According to the World Travel \& Tourism Council (WTTC), the tourism sector is estimate to carry on growing at $4 \%$ annually, one of the fastest industries around the world. The growth of tourism has shown considerable flexibility worldwide. Despite slow economic growth in European countries and other advanced economies, the number of international travelers keeps on rising. The World Tourism Organization further estimated that the global tourism population will grow to 1.6 billion people and the global tourism revenue will increase to 200 billion US dollars up to 2020. Therefore, it can be a surveillance that the tourism industry plays as a major role in the global economic expansion. The hotel industry is progressively more operating through extended periods of instability. Therefore, successful managers search for comprehending the impact of diverse shocks on their operations and to build up the tools required to deal with the consequences. The hotel industry is rendering to 
different operation risks and looking for improving their operational efficiency and performance. (World Economic Forum, 2015).

The tourism industry makes an important contribution to Taiwan's foreign exchange earnings. The hotel sector provides many functions such as accommodation, shopping, social activities, conference place, and entertainment (Chang \& Lu, 2006). For tourism industry in Taiwan, International tourist arrivals had increased from 2624037 visitors (in 2000) to 9910204 ones (in 2014). Foreign tourists spent 3.7 billion US dollars in 2000 but increased to 12.32 billions in 2013 in Taiwan. It is suggested that the hotel sector makes a great contribution to the tourism industry in Taiwan. The expenditures of international tourists and the number of international hotels in Taiwan are presented in Table 1.

Table 1. Number of visitors and international hotels in Taiwan (2000-2013)

\begin{tabular}{cccccc}
\hline Year & No. of Visitors & $\begin{array}{c}\text { Spending Per Person Per } \\
\text { Day (US\$) }\end{array}$ & $\begin{array}{c}\text { Average Length of Stay } \\
\text { (Nights) }\end{array}$ & $\begin{array}{c}\text { No of International } \\
\text { Tourist Hotels in Taiwan }\end{array}$ & No of Room in Taiwan \\
\hline 2000 & $2,624,037$ & 192.52 & 7.40 & 56 & 17,057 \\
2001 & $2,831,035$ & 207.77 & 7.37 & 58 & 17,815 \\
2002 & $2,977,692$ & 204.15 & 7.54 & 62 & 18,790 \\
2003 & $2,248,117$ & 166.08 & 7.97 & 62 & 18,776 \\
2004 & $2,950,342$ & 180.52 & 7.61 & 61 & 18,705 \\
2005 & $3,378,118$ & 207.50 & 7.10 & 60 & 18,385 \\
2006 & $3,519,827$ & 210.87 & 6.92 & 60 & 17,830 \\
2007 & $3,716,063$ & 215.21 & 6.52 & 60 & 17,733 \\
2008 & $3,845,187$ & 211.46 & 7.30 & 61 & 18,092 \\
2009 & $4,395,004$ & 216.30 & 7.17 & 64 & 18,645 \\
2010 & $5,567,277$ & 221.84 & 7.06 & 68 & 19,894 \\
2011 & $6,087,484$ & 257.82 & 7.05 & 70 & 20,382 \\
2012 & $7,311,470$ & 234.31 & 6.87 & 70 & 20,339 \\
2013 & $8,016,280$ & 224.07 & 6.86 & 71 & 20,434 \\
\hline
\end{tabular}

Data Source: Tourism Bureau (2014).

Hence, this paper aims to explore the operation performance of international hotels in Taiwan. Its purposes are as follows:

1) Understanding relative operational performance of international hotels.

2) Assessing managerial efficiency of international hotels.

3) Raising operational efficiency by technology and management activity.

This study contributes to the field of banking sector by comparing the performance and efficiency of commercial banks in Japan and Taiwan (Lu, Liang, \& Lee, 2013). This paper is organized as follow: section two reviews the relevant literature on banking industry using DEA and Malmquist Index. Section three introduces DEA and Malmquist Index briefly. Section four discusses methodology and samples. Section five presents findings and results. In the final section, conclusions and suggestions for further research are presented.

\section{Literature Review}

There are a range of study have been studied in the field of hotel performance using different methodologies and techniques, such as DEA or Malmquist Index to examine the operational performance and efficiency (Wu \& Tsai, 2011; Barros \& Dieke, 2008). Yu and Tsai (2014) examine that public transport facilities and medical services in different regions may influence the efficiency of international hotels in Taiwan. First, they use DEA method to evaluate the cost efficiency of international tourist hotels in Taiwan between 1998 and 2009. Second, we regression was used to estimate the effect of transportation and hospital services in terms of cost efficiency. It is found that the distance between MRT station and hotels has negatively correlation.

Honma and Hu (2012) employ both DEA and stochastic frontier analysis (SFA) to investigate the efficiency of hotels in Japan during the period of 2004 to 2008. According to the results by DEA, it is found that more than $50 \%$ of Japanese hotels apply increasing returns to scale technologies and that they can grow to be more efficient by expanding their businesses. The results from DEA also shows that hotel company listed on the Tokyo stock market has significant, positive impacts on efficiencies, but the distances between international airports and 
hotels have significant, negative impacts on hotel efficiencies in Japan. Huang et al. (2012) exercise a hybrid DEA model, in which the impartial inputs are assessed with a radial quantify and the non-proportionate inputs are assessed with a non-radial measure with the intention of evaluating the impact of marketing cost on the efficiency of international hotels in Taiwan. It is found that the inadequacy caused from surplus marketing cost is the major cause for lower efficiency in many international hotels, particularly to chain hotels and hotels that provide to domestic customers. Through the technology measurement, it is found that the consumption of marketing resources is more effective for self-regulating, city-base hotels.

Wu et al. (2011) use a non-radial DEA model to evaluate the operational efficiency of 23 international hotels in Taipei in 2006. The DEA model includes four inputs: (1) total number of rooms, (2) total number of employees, (3) food and beverage (F\&B) capacity, and (4) total operating cost, and three outputs: (1) guest room revenues, (2) F\&B revenues, and (3) other revenues). It is found that the DEA models present not only diverse performance measurements for the international hotels but also special benchmarks from different viewpoints for improving efficiency. $\mathrm{Wu}$ et al. (2013) offer a benchmarking framework to assess the efficiency and effectiveness of the hotel industry. A dynamic DEA approach is used to categorize the high performers. The DEA approach is used to perform a ranking under an input and output consumption. The results show that 9 out of 80 international hotels are identified as the maintained high performances. These hotels have business strategies in terms of staff, products, prices, and customers in Taiwan between 2006 and 2010.

Chiu and $\mathrm{Wu}$ (2010) use the context-dependent DEA model to examine the operating efficiency of 49 international hotels in Taiwan between 2004 and 2006. This DEA model is able to assess the magnetism of international hotels with comparative efficiency and the progress of international hotels with poorer efficiency. It is found that 17 out of the 49 have operating progress values in all levels. Barros and Alves (2004) examine the efficiency of a Portuguese chain-hotel company. DEA method is used to estimate total factor productivity change (TFPC), but breaking it down into technical efficiency change (TEC) and technological change (TC). The benchmarking process used is a domestic one that compares hotels with each other. The hotels are ranked according to their total productivity change (TPC). It is found that some hotels had productivity growth but others experienced a decline in the period of 1999 to 2001.

\section{Data Envelopment Analysis: Theory and Empirical Model}

This study exercises the Data Envelopment Analysis (DEA) to investigate the operational performance of international hotels in Taiwan. Over the past decades, DEA has extended into a well-liked methodology for assessing the comparative efficiencies of decision making units (DMUs). DEA technique permits an assessment of the efficiency and performance comparative to a best practice technology. Efficiency is a broader observation and engages choosing of optimum levels. Hotel efficiency may be segregated into scale, capacity, and technical efficiency. As contrasting to parametric techniques such as regression or Structural Equation Model (SEM), DEA technique does not assume that the corresponding optimized regression equation relates to all DMUs. A DMU is a component that produces outputs and exercises inputs, in this paper, each hotel represents a DMU. The DEA method holds constructing a non-parametric production frontier rooted in the valid input-output data in the sample relating to measured efficiency (Coelli, Prasada Rao, \& Battesse, 2001). DEA is a non-stochastic and non-parametric programming to calculate the comparative efficiency of DMUs with normal inputs and outputs. As to the DEA theoretical basis, we can separate into basic principle of the DEA and the Malmquist Index. This method can identify the most efficiency DMU among all the pronouncement units. It does not require to specific a weighted index, but can lever multiple inputs and multiple outputs. Moreover, it also offers the contribution of each variety of input and output to the comparative efficiency. In addition, this method can propose improvement suggestions for the inefficiency decision units and with impartiality and objectivity to assess the efficiency (Sufian, 2012). The DEA estimation evaluates each of the international hotel in the sample with the one that is the best exercise DMU in this research.

It is suggested that the choice of technique have an indispensable role in assessing efficiency and operational performance. DEA has been approved as a methodology for performance evaluation (Charnes, Cooper, \& Rhodes, 1978). Some reasons make DEA preferable to the other techniques, which are normally used to recognize the best-practices technology frontiers. Firstly, DEA estimations are reliable and normally come together faster than estimates obtained by Stochastic Frontiers Analysis (SFA). Secondly, DEA can offer neutral estimates of productivity although there is no single primary production technology. Finally, DEA estimates are more greatly correlated with predictable performance measures by comparison between research of applying DEA and SFA to hotel sector.

This study makes use of the DEA model such as competence analysis and sensitivity analysis in four modes. 
First, efficiency testing, Farrell (1957) defines the generally efficiency as the product of technical efficiency and allocates efficiency in general. Aalternatively, Banker, Charnes, and Cooper, (1984) crumbled the technical efficiency into the product of the pure technical efficiency and the scale efficiency. Second, return to scale analysis, with the DEA to compute the amount of the collective parameter $(\lambda)$ for each DMU, it can be identified which scale level stayed for the DMU. If $\Sigma \lambda>1$, it shows that the production of this DMU is in excess of the optimal scale. It is owned by the increasing return to scale. If $\Sigma \lambda<1$, it shows that the production of this DMU is under the optimal scale. It belongs to the decreasing return to scale. If $\Sigma \lambda=1$, it shows that the production of this DMU is on the optimal scale. It fits in the constant return to scale. In a revised model, it adds $\mathrm{u}_{0}$. If $-\mathrm{u}_{0}$ (negative $\mathrm{u}_{0}$ ) is greater than 0 (i.e. $\mathrm{u}_{0}$ itself is negative), then it corresponds to the line of the production boundary belonging to the increasing return to scale (IRS) (Banker et al., 1984). If $-\mathrm{u}_{0}$ equals to 0 , and then it corresponds to the line of the production frontier belonging to the constant return to scale (CRS). If $-\mathrm{u}_{0}$ is less than 0 , then it corresponds to the line of the production frontier belonging to the decreasing return to scale (DRS).

Third, slack variable analysis, this variable analysis can present the information of the resource consumption. It is not only for the foundation of goal setting, but also for understanding how much improvement for the evaluated DMU. For example, an inefficient evaluated DMU is called k. Its input set is $\left(\mathrm{X}_{\mathrm{ik}}, \mathrm{Y}_{\mathrm{rk}}\right)$. If the optimal solution is $\left(\theta^{*}, \lambda^{*}, \mathrm{~S}_{\mathrm{r}}^{+*}, \mathrm{~S}_{\mathrm{i}}^{*}\right),\left(\lambda_{1}^{*}, \lambda_{2}{ }^{*}, \ldots, \lambda_{\mathrm{n}}{ }^{*}\right)$, the protuberance of the $\left(\mathrm{X}_{\mathrm{ik}}, \mathrm{Y}_{\mathrm{rk}}\right)$ on the efficiency frontier is as following:

$$
\begin{gathered}
X_{i k} *=\theta^{*} X_{i k}-S_{i}^{-*}, i=1, \ldots, m \\
Y_{r k} *=Y_{r k}+S_{r}^{+*}, r=1, \ldots, S
\end{gathered}
$$

It can be found the difference of $\left(\mathrm{X}_{\mathrm{ik}}, \mathrm{Y}_{\mathrm{rk}}\right)$ to the compare object as follows:

$$
\begin{aligned}
& \Delta X_{i k}=X_{i k}-X_{i k}{ }^{*}, i=1, \ldots, m \\
& \Delta Y_{r k}=Y_{r k}-Y_{r k}{ }^{*}, r=1, \ldots, S
\end{aligned}
$$

That is to say, the evaluated DMU $\mathrm{k}$ can advance its efficiency by reducing input of $\Delta \mathrm{X}_{\mathrm{ik}}$ and increasing output of $\Delta \mathrm{Y}_{\mathrm{rk}}$.

Fourth, sensitivity analysis, the efficiency measured by the DEA is a comparative efficiency. If the number of the appraised DMU changes, its comparative efficiency will be changed as well. When input items changed, it has to repeat the DEA and to examine the efficiency value for the evaluated DMU. Consequently, any factor value changed it has to re-execute the programming model. Farrell (1957) recommended a method to assess efficiency. The most important assumption is production technique fixed to compute the distance of the DMU to the production frontier by using this production efficiency index as a criterion to evaluate firm operational performance. If add time factor into the model, it belongs to various period model. Production technique will be changed as a time variation. Therefore on evaluating production efficiency, it should consider the variation of the production technique. Färe, Grosskopf, Lindgren, and Roos (1992) developed Malmquist production index (MPI), in which it can resolve the aforementioned predicament. Productivity change can be decomposed into efficiency change $(E C)$ and technical change $(T C)$ by using remote function to estimate these two components of the MPI. Then utilize it to discover the reasons of the firm productivity change.

Before using MPI, we require to describe distant function. Assume it has $\mathrm{n}$ DMUs with $\mathrm{m}$ inputs and s outputs. Let $\mathrm{t}=1,2,3, \ldots ., \mathrm{T}$, input vector is $X^{t} \in R_{+}^{m}$, output vector is $Y^{t} \in R_{+}^{m}$, production technique $T^{t}$ is closed, non-empty, convex set. Input and output are free disposal. At the $\mathrm{t}$ term, production technique can express as $T^{t}=\left\{\left(X^{t}, Y^{t}\right), X\right.$ can produce $\left.Y\right\}$. According it, for any vector of $\left(X^{t}, Y^{t}\right)$, Shephard (1970) defined distant function as follows:

$$
D_{o}^{t}\left(X^{t}, Y^{t}\right)=\inf \left\{\theta:\left(X^{t}, Y^{t} / \theta\right) \in T^{t}\right\}, t=1,2,3, \ldots, T
$$

Malmquist input oriented productivity index was defined by Caves, Christensen, and Diewert, (1982) as following:

At term $t$,

$$
M_{o}^{t}=\frac{D_{o}^{t}\left(X^{t+1}, Y^{t+1}\right)}{D_{i}^{t}\left(X^{t}, Y^{t}\right)}
$$

At term $t+1$, 


$$
M_{o}^{t+1}=\frac{D_{o}^{t+1}\left(X^{t+1}, Y^{t+1}\right)}{D_{o}^{t+1}\left(X^{t}, Y^{t}\right)}
$$

The MPI definition used is the geometric average of the $t$ and $t+1$ term of the Malmquist input oriented index created by Caves et al. (1982). It is stated as follows:

$$
M_{o}\left(X^{t+1}, Y^{t+1}, X^{t}, Y^{t}\right)=\left[\frac{D_{o}^{t+1}\left(X^{t+1}, Y^{t+1} \mid C R S\right)}{D_{o}^{t+1}\left(X^{t}, Y^{t} \mid C R S\right)} \times \frac{D_{o}^{t}\left(X^{t+1}, Y^{t+1} \mid C R S\right)}{D_{o}^{t}\left(X^{t}, Y^{t} \mid C R S\right)}\right]^{1 / 2}
$$

It supposed on the constant return to scale (Fare et al., 1992; Caves et al., 1982). Two periods of the distant function are $D_{o}^{t}\left(X^{t}, Y^{t}\right)$ and $D_{o}^{t+1}\left(X^{t+1}, Y^{t+1}\right)$. It is also involved with two inter-temporal input distant function, $D_{o}^{t+1}\left(X^{t}, Y^{t}\right)$ and $D_{o}^{t}\left(X^{t+1}, Y^{t+1}\right)$. If $M_{o}\left(X^{t+1}, Y^{t+1}, X^{t}, Y^{t}\right)>1$, it shows that the productivity has some enhancement for the evaluated DMU. If $M_{o}\left(X^{t+1}, Y^{t+1}, X^{t}, Y^{t}\right)<1$, the productivity of the evaluated DMU ca be considered as declining.

MPI can be separated into the product of efficiency change $(E C)$ and technical change $(T C)$. Thus, the express (3) can be re-written as:

$$
\begin{gathered}
M_{o}\left(X^{t+1}, Y^{t+1}, X^{t}, Y^{t}\right)=\frac{D_{o}^{t+1}\left(X^{t+1}, Y^{t+1} \mid C R S\right)}{D_{o}^{t}\left(X^{t}, Y^{t} \mid C R S\right)}\left[\frac{D_{o}^{t}\left(X^{t+1}, Y^{t+1} \mid C R S\right)}{D_{o}^{t+1}\left(X^{t+1}, Y^{t+1} \mid C R S\right)} \times \frac{D_{o}^{t}\left(X^{t}, Y^{t} \mid C R S\right)}{D_{o}^{t+1}\left(X^{t}, Y^{t} \mid C R S\right)}\right]^{1 / 2} \\
E C(C R S)=\frac{D_{o}^{t+1}\left(X^{t+1}, Y^{t+1} \mid C R S\right)}{D_{o}^{t}\left(X^{t}, Y^{t} \mid C R S\right)} \\
T C(C R S)=\left[\frac{D_{o}^{t}\left(X^{t+1}, Y^{t+1} \mid C R S\right)}{D_{o}^{t+1}\left(X^{t+1}, Y^{t+1} \mid C R S\right)} \times \frac{D_{o}^{t}\left(X^{t}, Y^{t} \mid C R S\right)}{D_{o}^{t+1}\left(X^{t}, Y^{t} \mid C R S\right)}\right]^{1 / 2}
\end{gathered}
$$

In expression (5), if $E C(C R S)>1$, it designates efficiency enhancement. On the other hand, as $E C(C R S)<1$, the efficiency is worsening. When efficiency is improved, it shows that the correct administration and decision making cause efficiency improvement, $E C(C R S)>1$. In contrast, it indicates improper management and decision making cause $E C(C R S)<1$. In express (6), if $T C(C R S)>1$, it shows technique progress. $T C(C R S)<1$, it indicates technique regressed.

Though Malmquist productivity index is measured in constant return to scale, it also can compute the variable return to scale. In this case, the term of the $E C(C R S)$ at expression (5) can be decomposed into two terms: pure technical efficiency change, PTEC(VRS) and scale efficiency change (SEC). These two segments are defined by the following (7) and (8).

$$
\begin{gathered}
\operatorname{PTEC}(V R S)=\frac{D_{o}^{t+1}\left(X^{t+!}, Y^{t+1} \mid V R S\right)}{D_{o}^{t}\left(X^{t}, Y^{t} \mid V R S\right)} \\
S E C=\left[\frac{D_{o}^{t+1}\left(X^{t+1}, Y^{t+1} \mid C R S\right)}{D_{o}^{t+1}\left(X^{t+1}, Y^{t+1} \mid V R S\right)}\right] /\left[\frac{D_{o}^{t}\left(X^{t}, Y^{t} \mid C R S\right)}{D_{o}^{t}\left(X^{t}, Y^{t} \mid V R S\right)}\right]
\end{gathered}
$$

Expression (7) is the ratio of two phrases for the variable return to scale. If $P T E C(V R S)<1$, it points to efficiency degenerating. If $P T E C(V R S)>1$, it points to efficiency improvement. The similar in express (8), as $S E C>1$, it indicates production scale at the term of $\mathrm{t}+1$ relative to the term of $\mathrm{t}$ is more and more near the constant return to scale and regularly approaching long run optimal scale. If $S E C<1$, it points to production scale at the term of $t+1$ relative to the term of $t$ is more and more deviated the constant return to scale. Based on the aforementioned, Malmquist productivity index can be decomposed into PTEC, SEC, and TC. The relationship between these variables is shown as following:

$$
\left.M_{i}\left(Y^{t+1}, X^{t+1}, Y^{t}, X^{t}\right)=E C(C R S) \times T C(C R S)=P T E Q V R S\right) \times S E C \times T C(C R S)
$$

\section{Research Methods}

It is an advantage to make use of DEA and Malmquist Index in evaluating performance of international hotels since the techniques do not need to employ specified functional form. This paper aims to examine the long-term trend in efficiency changes of 28 international hotels in Taipei (see Table 2). 
Table 2. Samples of international hotels in Taipei

\begin{tabular}{cc}
\hline DMU & International Hotels in Taipei \\
\hline 1 & The Grand Hotel \\
2 & The Ambassador Hotel \\
3 & Imperial Hotel Taipei \\
4 & Gloria Prince Hotel \\
5 & Emperor Hotel \\
6 & Hotel Riverview Taipei \\
7 & Caesar Park Taipei \\
8 & Golden China Hotel \\
9 & San Want Hotel \\
10 & Brother Hotel \\
11 & Santos Hotel \\
12 & The Landis Ritz Hotel \\
13 & United Hotel \\
14 & Sheraton Taipei Hotel \\
15 & Hotel Royal Taipei \\
16 & Howard Plaza Hotel \\
17 & Grand Hyatt Taipei \\
18 & Grand Formosa Regent Taipei \\
19 & The Sherwood Hotel Taipei \\
20 & Far Eastern Plaza Hotel (Taipei) \\
21 & The Leofoo Hotel \\
22 & First Hotel \\
23 & Astar Hotel \\
24 & Empress Hot \\
25 & Hotel Flowers \\
26 & The Riviera Hotel \\
27 & Gala Hotel \\
28 & Cosmos Hotel \\
\hline & \\
\hline &
\end{tabular}

The data used in the study were collected from published annual reports of Taiwan Tourism Bureau. The test period in this research is between 2000 and 2014 as we hope to study the impact of the 2008 financial crisis on the evolution of efficiency scores of international hotels in Taipei. Table 3 shows that the input and output variables used in the study. It includes inputs: (1) numbers of rooms, (2) number of employee at room department, (3) number of employee at F\&B department, (4) number of employee at administration department, and (5) number of employee at other department, and outputs: (1) room revenue, and (2) total revenue (Wu \& Tsai, 2011; Barros \& Dieke, 2008).

Table 3. Variables of inputs and outputs

\begin{tabular}{llll}
\hline Inputs & & Mean & Std. \\
\hline Input 1 (IP1) & No. of Rooms & 294.08 & 186.95 \\
Input 2 (IP2) & No. of staff at Room Dep. & 97.26 & 72.56 \\
Input 3 (IP1) & No. of staff at F\&B Dep. & 157.52 & 152.61 \\
Input 4 (IP1) & No. of staff at Adm. Dep. & 51.66 & 48.87 \\
Input 5 (IP1) & No. of staff at Other Dep. & 32.65 & 36.56 \\
Outputs & & & \\
Output 1 (OP1) & Room Revenue & 19599775.93 & 19039623.27 \\
Output 2 (OP2) & Total Revenue & 64997161.49 & 67579041.19 \\
\hline
\end{tabular}

\section{Results}


The Table 4 shows that total efficiency has been steady improved for the international hotels between 2000 and 2015. However, total efficiency showed a decline from 2008 to 2009. This indicated that the operation of international hotels in Taipei is not on the optimal scale during the financial crisis. It is suggested of having some rooms for improvement regarding human resource utilization. Concerning the technical efficiency change (TEC), it's a little improved during 2003 to 2008, but profoundly decline between 2008 and 2009. On the other hand, the technical efficiency change had recovered between 2009 and 2011. For the scale efficiency change (SEC), the change rate in the period of 2006-2007 is 1.048, but the rate is 0.959 in the following period of 2007-2008. This shows that production scale was declining during the financial crisis. However, this rate had recovered from 2008 to 2009. Regarding the productivity change rate, it declines gradually from 2004 to 2009. However, it drops deeply in the period of 2008-2009. After the crisis, it keeps steady.

Table 4. Malmquist index summary of annual means

\begin{tabular}{|c|c|c|c|c|c|}
\hline Period & $\begin{array}{c}\text { Technical efficiency } \\
\text { change (1) }\end{array}$ & Technical change (2) & $\begin{array}{c}\text { Pure technical change } \\
\text { (3) }\end{array}$ & $\begin{array}{l}\text { Scale efficiency change } \\
\text { (4) }\end{array}$ & $\begin{array}{c}\text { Total factor productivity } \\
\text { change (5) }\end{array}$ \\
\hline $2000-2001$ & 0.940 & 0.947 & 0.961 & 0.979 & 0.890 \\
\hline $2001-2002$ & 0.938 & 1.065 & 0.977 & 0.961 & 1.000 \\
\hline $2002-2003$ & 0.975 & 1.088 & 0.951 & 1.024 & 1.061 \\
\hline 2003-2004 & 1.040 & 0.854 & 1.027 & 1.012 & 0.887 \\
\hline 2004-2005 & 1.006 & 1.166 & 1.035 & 0.971 & 1.172 \\
\hline $2005-2006$ & 1.032 & 1.014 & 1.017 & 1.015 & 1.046 \\
\hline 2006-2007 & 0.985 & 0.995 & 0.939 & 1.048 & 0.979 \\
\hline $2007-2008$ & 1.026 & 1.058 & 1.069 & 0.959 & 1.086 \\
\hline 2008-2009 & 0.921 & 0.866 & 0.951 & 0.968 & 0.797 \\
\hline 2009-2010 & 1.015 & 1.147 & 0.975 & 1.040 & 1.163 \\
\hline 2010-2011 & 1.096 & 1.060 & 1.066 & 1.029 & 1.162 \\
\hline 2011-2012 & 0.966 & 0.972 & 0.971 & 0.995 & 0.939 \\
\hline 2012-2013 & 0.975 & 1.136 & 0.982 & 0.993 & 1.108 \\
\hline $2013-2014$ & 1.054 & 1.015 & 1.026 & 1.027 & 1.070 \\
\hline 2014-2015 & 0.993 & 0.968 & 1.011 & 0.983 & 0.961 \\
\hline Mean & 0.996 & 1.019 & 0.996 & 1.000 & 1.015 \\
\hline
\end{tabular}

Given that the total factor productivity (TFP) is a multiplicative composite of technical efficiency change (TEC) and Technological change (TC), the most important source of productivity improvements can be determined by evaluating the values of TEC and TC. On the other hand, the productivity improvements demonstrated can be the consequences of efficiency achievements (failure), technological progress (retrogress) or both. The generally efficiency change is the product of pure technical change (PTE) and Scale efficiency change (SEC) in the same approach. Table 5 shows the total factor productivity change (TFPC) in ranking order from the uppermost to the lowest hotel descending. All the indices in the Table 5 are mean values and the total factor productivities change (TFPC) is computed with reference to the previous technological change (TC). In this situation, it means that these international hotels are taking advantages of innovation and hotel technology to accept new methods of bringing services. From the Malmquist indices in Table 4, the international hotel with highest total factor productivity change (TFPC) intensification is Imperial Hotel Taipei. It comes from 9.4 per cent raise in technological change over the period of 2000-2015. On the contrary, First Hotel had the lowest total factor productivity change (TFPC) and slightly regressed by 5.4 per cent.

In Table 5, 28.57\% of the hotels are lower the mean score in terms of total factor productivity change (TFPC). It indicates that a small part of international hotels in Taipei did not have gains in total productivity between 2000 and 2015. The mean score is 1.015 , confirming that for the majority of the international hotels in Taipei increased in the study period. Most of the productivity decrease is as a result of technological efficiency change (TEC). We can see that the score of the total factor productivity change (TFPC) is one or higher than one for $71.43 \%$, showing that most of the international hotels in Taipei experience benefits in total factor productivity change (TFPC) between 2000 and 2015.

The scores of technical efficiency change (TEC) are defined as the dispersion of best-practice technology in the management of the action and are recognized to technical experience in the international hotels in Taipei. The breakdown of the technical efficiency change (TEC) into pure technical efficiency change (PTEC) and scale 
efficiency change (SEC) demonstrate combined outcomes, with some hotels obtaining coexisting gains in the pure technical efficiency change (PTEC) and scale efficiency change (SEC). However, others attaining gains in one but losses in the other. The improvement in pure technical efficiency change (PTEC), which means an enhancement in managerial capability, makes clear that there was speculation in firm aspects such as a balanced inputs and outputs, best-practice methods, and quality upgrading. The scale efficiency change (SEC) increases and the mean value of pure technical efficiency change (PTEC) change is 0.996 and of scale efficiency change (SEC) change is 1.000 .

Table 5. Hotels ranking by total factor productivity change of malmquist index

\begin{tabular}{|c|c|c|c|c|c|c|}
\hline Rank & Hotel Name & $\begin{array}{c}\text { Technical } \\
\text { efficiency change } \\
\text { (1) }\end{array}$ & $\begin{array}{c}\text { Technical change } \\
\text { (2) }\end{array}$ & $\begin{array}{l}\text { Pure technical } \\
\text { change (3) }\end{array}$ & $\begin{array}{c}\text { Scale efficiency } \\
\text { change (4) }\end{array}$ & $\begin{array}{r}\text { Total factor } \\
\text { productivity } \\
\text { change (5) }\end{array}$ \\
\hline 1 & Imperial Hotel Taipei & 1.005 & 1.080 & 1.004 & 1.001 & 1.085 \\
\hline 2 & Caesar Park Taipei & 1.026 & 1.035 & 1.023 & 1.002 & 1.062 \\
\hline 3 & Hotel Riverview Taipei & 1.025 & 1.032 & 1.015 & 1.010 & 1.057 \\
\hline 4 & Cosmos Hotel & 1.000 & 1.055 & 1.000 & 1.000 & 1.055 \\
\hline 5 & Empress Hotel & 0.993 & 1.059 & 1.000 & 0.993 & 1.052 \\
\hline 6 & The Landis Ritz Hotel & 1.014 & 1.029 & 1.011 & 1.002 & 1.043 \\
\hline 7 & Astar Hotel & 1.007 & 1.035 & 1.000 & 1.007 & 1.042 \\
\hline 8 & Hotel Flowers & 1.003 & 1.036 & 1.003 & 1.001 & 1.039 \\
\hline 9 & Santos Hotel & 0.989 & 1.042 & 0.987 & 1.001 & 1.030 \\
\hline 10 & San Want Hotel & 1.015 & 1.014 & 1.011 & 1.003 & 1.029 \\
\hline 11 & Hotel Royal Taipei & 1.003 & 1.020 & 1.000 & 1.003 & 1.023 \\
\hline 12 & Emperor Hotel & 0.986 & 1.034 & 0.980 & 1.006 & 1.019 \\
\hline 13 & Grand Hyatt Taipei & 1.000 & 1.019 & 1.000 & 1.000 & 1.019 \\
\hline 14 & The Leofoo Hotel & 0.994 & 1.024 & 1.007 & 0.987 & 1.018 \\
\hline 15 & The Ambassador Hotel & 0.999 & 1.015 & 1.000 & 0.999 & 1.014 \\
\hline 16 & Gala Hotel & 0.969 & 1.043 & 0.975 & 0.994 & 1.011 \\
\hline 17 & Gloria Prince Hotel & 0.978 & 1.028 & 0.979 & 0.999 & 1.005 \\
\hline 18 & United Hotel & 0.992 & 1.010 & 0.996 & 0.996 & 1.003 \\
\hline 19 & Howard Plaza Hotel & 0.981 & 1.023 & 0.991 & 0.990 & 1.003 \\
\hline 20 & Golden China Hotel & 1.007 & 0.995 & 1.002 & 1.005 & 1.002 \\
\hline 21 & Far Eastern Plaza Hotel (Taipei) & 0.993 & 1.004 & 0.995 & 0.999 & 0.997 \\
\hline 22 & Grand Formosa Regent Taipei & 1.000 & 0.995 & 1.000 & 1.000 & 0.995 \\
\hline 23 & Brother Hotel & 0.966 & 1.022 & 0.964 & 1.003 & 0.988 \\
\hline 24 & The Riviera Hotel & 0.997 & 0.989 & 0.995 & 1.003 & 0.987 \\
\hline 25 & The Grand Hotel & 0.970 & 1.014 & 0.972 & 0.998 & 0.984 \\
\hline 26 & The Sherwood Hotel Taipei & 0.988 & 0.991 & 0.991 & 0.997 & 0.979 \\
\hline 27 & Sheraton Taipei Hotel & 1.000 & 0.958 & 1.000 & 1.000 & 0.958 \\
\hline \multirow[t]{2}{*}{28} & First Hotel & 1.000 & 0.949 & 1.000 & 1.000 & 0.949 \\
\hline & Mean & 0.996 & 1.019 & 0.996 & 1.000 & 1.015 \\
\hline \multicolumn{2}{|c|}{ Number of Efficient ratio $>1$} & $9(32.14 \%)$ & $22(78.57 \%)$ & $8(28.57 \%)$ & $13(46.43 \%)$ & $20(71.43 \%)$ \\
\hline \multicolumn{2}{|c|}{ Number of Efficient ratio $=1$} & $5(17.86 \%)$ & $0(0 \%)$ & $9(32.14 \%)$ & $5(17.86 \%)$ & $0(0 \%)$ \\
\hline \multicolumn{2}{|c|}{ Number of Efficient ratio $<1$} & $14(50 \%)$ & $6(21.43 \%)$ & $11(39.29 \%)$ & $11(35.71 \%)$ & $8(28.57 \%)$ \\
\hline
\end{tabular}

Technological change (TC) is the consequence of improvement, which is the accomplishment of new technologies by best-practice international hotels. These indexes are higher than one for a majority of the international hotels $(78.57 \%)$. It shows that innovation advance between 2000 and 2015 for most of the international hotels in Taipei, meaning that there was adequate speculation in new technologies and in satisfactorily improved skills.

On the whole, we study two amalgamations of technical efficiency change (TEC) and technological change (TC). Firstly, it is found that ten hotels, in which improvements in technical efficiency change (TEC) with technological change (TC). Second, it is found four hotels, in which improvements in technical efficiency change (TEC) with decline of technological change (TC). These four hotels need to move forward their 
administrative skills and operational scale with the intention of performance enhancement. In general, the mean total factor productivity change (TFPC) increase in the hotel sector over the period of 2000-2015 was 1.5 per cent. The major reason to this gain is technological change (TC). There was a slight decline in TEC and PTC $(0.4$ per cent). It is possible caused by organizational and human resources inefficiencies.

\section{Conclusions}

In this paper, we have assessed efficiency changes of international hotels in Taipei by using DEA and the Malmquist indices during the period 2000-2015. A panel data set of 28 international hotels in Taipei has been utilized. There is a profoundly drop in all changes but SEC between 2008 and 2009, which show the impact of financial crisis on the hotel industry in Taiwan. The findings of this study are anticipated to contribute remarkably to the existing knowledge on the performance and efficiency of the hotel sector in Taiwan.

One of the mainly significant findings indicates that overall efficiency in the international hotels in Taipei has improved after 2009. The annual means of the Malmquist index shows that the 2008 financial crisis had greatly impact in decreasing the technical efficiency change (TFC) that has caused to decline the total factor productivity (TFP). The findings suggest that the inefficiency of the international hotels in Taipei were largely due to technical efficiency change (TEC) rather than scale efficiency change (SEC). The empirical findings also suggest that the decline in the efficiency of the international hotels in Taipei were mostly due to technological efficiency change (TFC) and partly by scale efficiency change (SEC). TFC inefficiency had a big impact on the international hotels in Taipei. It shows the problems caused by deprived human resources management, employee skill issues and the incapability to provide proper services in order to improve their performance. During the period of 2000-2015, the empirical findings suggest that the inefficiency of the international hotels in Taipei were mostly due to technological efficiency change (TFC) and partly by scale efficiency change (SEC). The results also involve that some international hotels in Taipei may be too small to benefit from the economies of scale. Therefore, from the economic perspective, it is suggested that the relatively smaller international hotels in Taipei may move up their efficiency levels and performance by merger with other chain hotels or forming strategic alliances.

\section{References}

Banker, R., Charnes, A., \& Cooper, W. (1984). Some Models for Estimating Technical and Scale Inefficiencies in Date Envelopment Analysis. Management Science, 30(9), 1078-1092. http://dx.doi.org/10.1287/mnsc.30.9.1078

Barros, C. P., \& Dieke, P. U. C. (2008). Technical efficiency of African hotels. International Journal of Hospitality Management, 27(3), 438-447. http://dx.doi.org/10.1016/j.ijhm.2007.11.004

Barros, C., \& Alves, F. (2004). Productivity in the tourism industry. International Advances in Economic Research, 10(3), 215-225. http://dx.doi.org/10.1007/BF02296216

Caves, W., Christensen, R., \& Diewert, E. (1982). The economic theory of index numbers and the measurement of input, output, and productivity. Econometrica, 50, 1393-1414. http://dx.doi.org/10.2307/1913388

Chang, H., \& Lu, L. (2006). Effect of Service Orientation on Job Satisfaction, Organizational Commitment, and Intention of Leaving-An Empirical Study of the International Tourist Hotels in Taipei. Journal of Global Commerce and Management, 1, 1-14.

Charnes A, Cooper, W., \& Rhodes, E. (1978). Measuring the Efficiency of Decision Making Units. European Journal of Operations Research, 2(2), 424-444. http://dx.doi.org/10.1016/0377-2217(78)90138-8

Chiu, Y., \& Wu, M. (2010). Performance Evaluation of International Tourism Hotels in Taiwan-Application of Context-dependent DEA. INFOR: Information Systems and Operational Research, 48(3), 155-170. http://dx.doi.org/10.3138/infor.48.3.155

Coelli, T., Prasada Rao, S., \& Battesse, G. (2001). An Introduction to Efficiency and Productivity Analysis. Boston: Kluwer Academic Publishers, MA.

Färe, R., Grosskopf, S., Lindgren, B., \& Roos, P. (1992). Productivity changes in Swedish pharmacies 1980-1989: A non-parametric Malmquist approach. Journal of Productivity Analysis, 3(1), 85-101. http://dx.doi.org/10.1007/BF00158770

Farrell, M. (1957). The Measurement of Productive Efficiency. Journal of the Royal Statistical Society, 120, 253-281. http://dx.doi.org/10.2307/2343100 
Giannotti, C., Mattarocci, G., \& Spinelli, L. D. (2010). The relative importance of sector and regional factors in the hotel industry: Evidence from the Italian market. Journal of Property Investment \& Finance, 28, 162-180. http://dx.doi.org/10.1108/14635781011048830

Honma, S., \& Hu, J. (2012). Analyzing Japanese hotel efficiency. Tourism and Hospitality Research, 12(3), 155-167. http://dx.doi.org/10.1177/1467358412470558

Huang, C., Chiu, Y., Ting, C., \& Lin, C. (2012). Applying a hybrid DEA model to evaluate the influence of marketing activities to operational efficiency on Taiwan's international tourist hotels. Journal of the Operational Research Society, 63, 549-560. http://dx.doi.org/10.1057/jors.2011.58

Lu, L., Liang, S., \& Lee, Y. (2013). Application of Malmquist Indexes, Empirical Model and Data Envelopment Analysis: A Measure of Performance and Efficiency of Commercial Banks in Taiwan. British Journal of Economics, Management \& Trade, 4(3), 341-348. http://dx.doi.org/10.9734/BJEMT/2014/5565

Sufian, F. (2012). Developments in the efficiency of the Malaysian banking sector: The impacts of financial disruptions and exchange rate regimes. Progress in Development Studies, 12(1), 19-46. http://dx.doi.org/10.1177/146499341101200102

Tourism, B. (2015). Annual Report of Tourism. Ministry of Transportation and Communications, Taiwan.

UNWTO. (2010). Tourism Market Trends: World Overview and Tourism Topics. Madrid, Spain.

World Economic Forum. (2015). Travel \& Tourism Competitiveness Report 2015. Geneva, Switzerland.

Wu, J., Tsai, H., \& Zhou, Z. (2011). Improving efficiency in international tourist hotels in Taipei using a non-radial DEA model. International Journal of Contemporary Hospitality Management, 23(1), 66-83. http://dx.doi.org/10.1108/09596111111101670

Wu, W., Lan, L., \& Lee, Y. (2013). Benchmarking hotel industry in a multi-period context with DEA approaches: A case study. Benchmarking: An International Journal, 20(2), 152-168. http://dx.doi.org/10.1108/14635771311307650

Yu, L., \& Tsai, H. (2014). Regional Traffic \& Medical Services and Cost Efficiency of International Tourist Hotels in Taiwan. International Business Research, 7(10), 36-46.

Yuwa, H., \& Choong, D. (2015). Global Destination Cities Index 2015. MasterCard Company, New York: USA. Retrieved

from http://newsroom.mastercard.com/wp-content/uploads/2015/06/MasterCard-GDCI-2015-Final-Report1.pdf

\section{Copyrights}

Copyright for this article is retained by the author(s), with first publication rights granted to the journal.

This is an open-access article distributed under the terms and conditions of the Creative Commons Attribution license (http://creativecommons.org/licenses/by/3.0/). 